\title{
The Effective of Using 5 Simple Steps (QSCCS) Learning Activities on Facebook to Promote Self-learning in the 21st Century in Technology Printing and Advertising Course for Undergraduate Students in Education Technology and Communications
}

\author{
Tipparat Sittiwong*, Thanet Wongnam
}

Faculty of Education, Naresuan University, Thailand

Copyright (C) 2015 by authors, all rights reserved. Authors agree that this article remains permanently open access under the terms of the Creative Commons Attribution License 4.0 International License

\begin{abstract}
The objectives of this study were to: 1) study the result of implementing QSCCS with Facebook; 2) study students' opinions concerning the implementation of QSCCS with Facebook. The samples were 38 Technology and Communications undergraduates who attended Printing and Advertising Technology course in academic year of 2013. The information was gathered by using the achievement test regarding implementing QSCCS with Facebook and a questionnaire regarding students' opinions concerning implementing Qsccs. Later on, the information was analyzed to find percentage, mean, standard deviation, independent t-test, and problems conclusions and suggestions. The result showed that: 1) students achieved higher score after implementing QSCCS. The significance was .05; 2) students' opinions concerning implementing QSCCS with Facebook were high $(.=3.69,=.47)$. Once considered in all aspects, the aspect that achieved the highest mean was the one that allowed students to study on their own $(.=3.92,=.75)$. Following by implementing Facebook with learning in order to allow students and teachers to be able to communicate in more various ways $(.=3.82,=.61)$, finally, there were three aspects that achieved the same mean, which were: students were involved more in learning activities $(.=3.76,=.71)$, students were able to study by themselves more $(.=3.76$, $=.71$ ), and Facebook helped students to enjoy learning a lot more $(.=3.76,=.71)$.
\end{abstract}

Keywords QSCCS, Learning Process, 5-step Learning Process, Facebook, Social Media

\section{Introduction}

Global $21^{\text {st }}$ century teachers need to transform themselves from "teaching" as a coach. From the training project for learning, integrated intelligence flourish from within, not from teachers where students put their knowledge into the brain by themselves (New Review. 2013). From the above it is seen that in the world of learning in the 21 st century students should have the essential skills, such as critical thinking, problem solving, creativity skills, and most importantly communicative and collaborative skills. Learning styles of students have changed dramatically from the former classes, that is to say, in the past, the students will be the only recipient, now it has changed to students are more active in class that means they have to seek self-knowledge by themselves. Moreover, in present days, internet has become part of human's life. Students also find their ways to work with internet one way or another. They use internet for self-studying, analyze and calculate data, therefore, the internet is considered an aid in teaching, for it is used as a tool for enhancing students' skills. In the $21^{\text {st }}$ century, it is suggested that learning of students should emphasizes on the importance of giving the students pursuing self-knowledge. From such significant results in improvement of teaching in elementary school, secondary and higher education, for they have changed the way of teaching to be more collaborative, particularly in higher education which focused on the students to learn on their own. The study found that from the process of teaching activities using the paradigm 5 stairs, they can promote self-learning skills of the students in $21^{\text {st }}$ century.

QSCCS or as we called paradigm 5 stairs means teaching to assist learners and potential of individuals. As in researching skills, the basic knowledge needed for this skill is critical thinking, effective communication, and cooperative life skill (Office of the High School. Office of the Basic Education Ministry of Education, 2013). Paradigm 
Learning QSCCS comprised of 1. Learning by asking questions (Learning to Question) 2. Learning seek information (Learning to Search) 3. Learning to build knowledge. (Learning to Construct) 4. Learning to communicate (Learning to Communicate) 5. Learning to society (Learning to Serve). This learning process, thus, fulfills the $21^{\text {st }}$ century by encouraging the students with skills in observation, then hypothesis. Such skills are parts of being effective citizen of the $21^{\text {st }}$ century. This approach has been acquired by many schools already. Many schools have introduced a tool call Social Tool which means using social media to foster self-learning. This tool, especially Facebook, gain popularity in all age groups and certainly help promoting $21^{\text {st }}$ century learning.

Facebook is an online social networking service where user can create a profile, add other users as friends and exchange messages. They can also post photos and posted video clips, even write articles or blogs. The activities are widely available on Facebook (Megan Poore. 2013). However, in year 2012, Facebook has been used increasingly all over the world. Over 18 Million People use Facebook counts for $85 \%$. Thus, the use of Facebook has grown from last year $24 \%$ and the number of public posts per day on Face book is approximately $31,000,000$ per day, and the interaction (Likes, Comments, Shares) at an average of 624,000 times a day (World Map of Social Networks 2009-2012, 2513). The study found that Facebook can promote self-learning and promote effective learning for the students. By Objectives (Thiparat rights Wong. 2014 Nathapol lotus Urai, 2011. Nada Dabbagh, Anastasia Kitsantas, 2011).

Such importance, the research suggests that there should be an event for teaching led by Paradigm Learning 5 Steps including QSCCQ 1. Learning by asking questions (Learning to Question) 2. Learning seek information (Learning to Search) 3. Learning to build knowledge. (Learning to Construct) 4. Learning to communicate (Learning to Communicate) 5. Learning to society (Learning to Serve). They are considered ladders to help the students develop the knowledge by integrating with Facebook, a tool for self-learning as well that used to develop teaching skills, to promote learning and attitude that are required for being a good citizen of the 21 st century.

\section{Purpose of Research}

To study the effects of teaching activities with ladders 5 Step (QSCCS) Integrated with Facebook to promote self-learning of the $21^{\text {st }}$ century, together with course printing technology and advertising for undergraduate students of Technology and Communications.

The opinion of the students on the teaching activities with ladders 5 Step (QSCCS) Integrated with Facebook to promote self-learning of the $21^{\text {st }}$ century course printing technology and advertising for undergraduate students of Technology and Communications.

\section{Scope of Research}

\section{Population}

38 undergraduate Technology and Communications students learning technology, printing and advertising. Year 2013

\section{The Variables Used in the Study}

The variable is the use of teaching and learning activities with ladders fifth stage. (QSCCS) with Facebook.

The dependent variable is the result of studies and opinions on the activities of teaching a five step ladder. (QSCCS) with Facebook.

The content used in experiments: Course Technology 375366 printing and advertising. Year 2013

\section{Tools Used in Research}

The results of the research activities, teaching five stairs Step (QSCCS) together with Facebook, to promote self-learning in the 21 st century for Technology Printing and Advertising course, undergraduate Students Association for Educational Communications and Technology. The researchers used the results from the evaluation form comprised of 2Sections:

1. Achievement before and after learning activities taught by five steps (QSCCS) With Facebook to promote self-learning of the $21^{\text {st }}$ century course in printing technology and advertising.

2. Behavior Evaluation of the learning paradigm Step Ladder 5 (QSCCS).

3. Survey among students with learning activities with ladders 5 Step (QSCCS) With Facebook to promote self-learning of the $21^{\text {st }}$ century course printing technology and advertising.

\section{How to Conduct}

\subsection{Creation Tool}

- Construction of achievement before and after learning activities, teaching a five step ladder (QSCCS) with Facebook to promote self-learning courses in the $21 \mathrm{st}$ century printing technology and advertising.

- Behavior Evaluation create the learning paradigm stairs 5 Step (QSCCS)

- Survey among students with learning activities with ladders Step 5 (QSCCS) with Facebook to promote self-learning courses in the 21 st century printing technology and advertising.

\subsection{Data Collection}

Information collected in the course of printing technology 
and advertising is from $2^{\text {nd }}$ year 38 students in 2013 by assessing student achievement under the stairs 5 Step (QSCCS) in combination with Facebook. And the achievement was assessed at the end of the teaching process that means the end of the semester. Also their opinions will be assessed by using Likert Scale.

\subsection{Data Analysis}

I. An achievement before and after learning activities taught by five steps Step (QSCCS) with Facebook to promote self-learning of the $21^{\text {st }}$ century course in printing technology and advertising. Compare achievement before and after learning by finding the mean and statistical t-test Dependent.

II. Behavior Evaluation of the learning paradigm stairs5 Step (QSCCS) with Facebook. The researchers analyze by using statistical procedure to calculate average and standard deviation of individual items, information tables with description, and the third set threshold values. North of Liquor (Likert. Scale), which establishes a three-level scoring is a little more moderate. Then, defined criteria for interpretation of the criteria incorporated in the translation, is the average of the three levels are frequent.

III. The questionnaire for students, including students with learning activities with five stairs matches, (QSCCS) with Facebook to promote self-learning of the $21^{\text {st }}$ century course in printing technology and advertising. The research conducted by analyzing the data using a programming model for processing statistical data by using the mean and standard deviation to define individual messages and information. Table captions used the device prescribed threshold values of North of Liquor (Likert Scale). Then, define the criteria for the interpretation of the five levels that most agree, agree, agree moderately, agree less, and less possible.

\section{Results}

Results of teaching activities with 5 ladders (QSCCS) Integrated with Facebook to promote self-learning of the $21^{\text {st }}$ century course in printing technology and advertising from undergraduate students of Technology and Communications are as follows:

Results of teaching activities with ladders 5 Steps (QSCCS ) Integrated with Facebook to promote self-learning of the $21^{\text {st }}$ century course in printing technology and advertising for undergraduate students of Technology and Communications found more posttest scores than pretest due to the process of teaching students involved in the design, and learning plans by the pursuit of self-knowledge that will bring learning in the classroom. In addition, the content has to be there to share it with the classroom of the course, the student can reviewed the content they want at any time via Facebook.

The behavior of the learning paradigm Ladder 5 QSCCS step in the overall level. $(=2.85, .09)$ Including the search of knowledge and information (Learn to Search: S) for the creation of knowledge (Learn to Construct: C) communications and provide effective (Learn to Communicate: C) and social services and so on. Public Mind (Learn to Serve: S) due to the learning paradigm stairs 5 QSCCS encourage students to effect change. The outcomes resulted in developing collaborative learning. In particular, this method focuses on process rather than product. It made clear to the achievement by behavioral aspects. Clearly changes Consistent with the findings of the General Aviation WATTANA sacred obligation. (2553) Found that the development model followed by support for local teachers to bring the program into the curriculum of classroom teachers. It changes the role of learning with mentors who provide guidance, advising teachers on student's learning.

The opinions of the students on the teaching activities with ladders 5 Step (QSCCS) Integrated with Facebook to promote self-learning of the $21^{\text {st }}$ century course in printing technology and advertising. Overall, the high level considered each aspect. The opportunity for students to learn on their own or working together, in line with the research of God's Gorinchem Bong Pong debris. (2011) has done research on the topic "Results of the study by e-learning and collaborative learning through social media with the ability to use information and communications technology of undergraduates. Education Education Branch" found that the opinions of students toward learning with e-learning and collaborative learning through social media was at a good level $(=4.13$ And SD $=0.74)$ Kerr and the University Calendar (Curtin University), by using a discussion board on Facebook as a form of interaction with the students. The learners are more discussions about curriculum and homework. In particular, the students and staff began posting links to additional learning support tool in the group. But not as part of the reading of the official group shows that Facebook can create interaction between the learner and help in the exchange of ideas. Facebook in the activities of teaching allows students to communicate with instructors have more diversity. As Thiparat research (2014) suggested that social media is said as the technology has been applied to many online tools, knowledge management systems to the network. That can reduce inequality of access to knowledge resulting from the professional experiences of each season. Show that the use of Social media makes communication easier. And third, with an average of three equal sides, it showed that students participate in activities to learn, and has more opportunities for students to learn on their own, and learn to use Facebook allows students to learn with fun and learning at the pleasure. As the opinion of the students, it is concluded that the use of Facebook to help achieve self-mastery. The exchange of ideas and interaction is a feature of the century learners. 21

\section{REFERENCES}

[1] Admiral William WATTANA sacred obligation . (2553). 
846 The Effective of Using 5 Simple Steps (QSCCS) Learning Activities on Facebook to Promote Self-learning in the 21 st Century in Technology Printing and Advertising Course for Undergraduate Students in Education Technology and Communications

Development patterns to follow to help teachers bring the curriculum to local learning classroom teachers. . Prof. Thesis study. The., Silpakorn University, Nakhon Pathom .

[2] Nathapol lotus Urai . (. 2554 ). Learning management using Social Media in theory self-knowledge. Pathumthani: School development

[3] Thiparat the family . (2557). The study reviews the students with a knowledge management system to support teaching on the Internet. . Journal of Education University , 16 (2), 155-164. When searched 25 June 2557 From Http://www.tci-thaijo.org/index.php/ edujournal_nu / Article / View /. 17568/15685.

[4] Martin Vari glass Urai . (2556). Development of teacher quality, using the built in Coaching and Mentoring the Mentor Board of Education. University The Office of Basic Education, March 30. 2557 of

www.brs.ac.th/_files_school/.../65100487_1_20

131028-150244. ppt

[5] Office of the High School. Office of the Basic Education The
Ministry of Education . (2555). The guidelines of the revised international standards of teaching in schools. . Bangkok : Agricultural Cooperatives of Thailand .

[6] Dabbagh, N., \& Kitsantas, A. (2012). Personal Learning Environments, social media, and self-regulated learning: A natural formula for connecting formal and informal learning. The Internet and Higher Education, 15 (1), 3-8, (2011), doi: $10.1016 /$ j.iheduc. 2011.06 .002

[7] Poore, M. (in 2013). Using social Media in Classroom: a Best Practice Guide. London: SAGE Publications Ltd.

[8] Upbin, B., World Map of social networks, Forbes Magazine, Online, January 27, 2,012th.

[9] God's Pong chip Gorinchem Bong. (2554). Results of the study by e-learning and collaborative learning through social media with the ability to use information and communications technology of undergraduates. Education Education Branch . MA Thesis. M, Silpakorn University, Nakhon Pathom . Search on 25 June 2557 From http://www.thailis.com. 